ค]

columns of treatment and prevention. Although the outcome of some of these initiatives is not yet clear, there is now a greater emphasis on diverting those in conflict with the law from custodial sentences towards treatment. This edition has taken account of those who are sentenced to prison and those with mental disability whose substance misuse brings them into conflict with the law.

The assessment and treatment of those who misuse substances present forensic physicians with particular challenges which require skills and experience to ensure appropriate management. Good communication, working closely with custody officers, and shared responsibility for the safety and care of detainees with substance misuse problems are all important factors. In particular, the guidelines stress the importance of:

- forensic physicians' full participation in all aspects and at all stages of the healthcare of detainees with substance misuse/dependence problems

- providing advice to custody officers and others involved with detainees with substance misuse/dependence problems

- comprehensive contemporaneous records

- appropriate sharing of information in accordance with the law and the General Medical Council's advice on professional confidentiality

- all interventions being made with an awareness that the interests of the detainee as a patient are paramount.

The guidelines will be of immense value to all practitioners in helping and supporting detainees, and to the staff of law enforcement agencies who are involved in the care of detainees with substance misuse problems. They will also be useful for teaching purposes for medical and nursing staff and arrest referral officers.

\section{Psychiatric Services for Adolescents and Adults with Asperger Syndrome and Other Autistic-Spectrum Disorders}

\section{Council Report CR136, April} 2006, Royal College of Psychiatrists, f7.50, $40 \mathrm{pp}$

Autistic-spectrum disorders (ASD) are a complex group of developmental disorders frequently associated with comorbid psychiatric disorder, colouring their presentation and complicating their management. Presenting over a wide range of age and ability, they are encountered in all psychiatric specialties.

This report is a consensus view of the psychiatric services required for many with ASD in adolescence and adulthood. The focus is often on diagnosis, but this is only one part of a wider process of multidisciplinary assessment that should then flow on to management. Although the report focuses narrowly on psychiatry, it recognises that this is only one part of a more extensive range of services. It is a preliminary exercise, intended to inform the broader, multidisciplinary and multiagency approaches that are under way across the whole of the UK. It is addressed to psychiatrists, stakeholders in the development of ASD services and commissioners of adolescent and adult services, across all the psychiatric specialties.

After a description of the syndrome, its comorbidity and epidemiology, the report distinguishes diagnosis from the fuller, multidisciplinary assessment. Reviewing the methodology and difficulties of this process, it concludes that all psychiatrists should be able to recognise the syndrome, diagnosing it in clear-cut cases, and be aware of its implications. This has to be the subject of postgraduate training at all levels, from basic psychiatric training through to the consultant's continuing professional development.

Besides the lack of services specific to this population, people with ASD are poorly served by most standard services - in particular, those who are too old for adolescent services and too able for learning disability services. For those whose diagnosis is less straightforward or whose clinical management is more complex, there needs to be access to local specialist expertise and, where necessary, to tertiary specialist services. This applies particularly to the provision for psychiatric admission, whether as daypatients or in-patients, for a group of people for whom the usual clinical environment can be distressing and unhelpful. Psychiatric services need to improve through a combination of training, better liaison between the specialties and the development of specialist interest and tertiary services, the last including the development of autism-specific services both in the statutory and in the independent sectors.

Psychiatric services are overstretched by existing demands, so that any improvement will only come about if driven by service commissioners who recognise the shortfall and specifically support further developments. 